\title{
Synthesis and Trypanocidal Properties of New Coumarin-Chalcone Derivatives
}

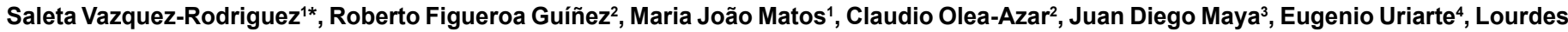
Santana ${ }^{4}$ and Fernanda Borges ${ }^{1}$

${ }^{1}$ CIQUP/Department of Chemistry and Biochemistry, Faculty of Sciences, University of Porto, Rua Campo Alegre 687, 4169-007 Porto, Portugal ${ }^{2}$ Department of Inorganic and Analytical Chemistry, Faculty of Chemical and Pharmaceutical Science, University of Chile, Casilla 233, Santiago, Chile ${ }^{3}$ Departamento of Molecular and Clinical Pharmacology, Faculty of Medicine, University of Chile, Santiago, Chile

${ }^{4}$ Department of Organic Chemistry, Faculty of Pharmacy, University of Santiago de Compostela, Campus Vida s/n, 15782, Santiago de Compostela, España

\begin{abstract}
With the aim of finding new chemical entities based on coumarin and chalcone scaffolds, new hybrid compounds 2-5 were designed and synthesized. The trypanocidal activity of these compounds was tested against the epimastigote, trypomastigote and amastigote stages of the Trypanosoma cruzi parasite. Cytotoxicity assays were also performed in RAW 264.7 and VERO cells. Compound 5 presented the highest trypanocidal activity of the series, with trypanocidal values higher than Nifurtimox for the trypomastigote and epimastigote stages., but presenting cytotoxic effects in the mammalian cells. A SAR study suggested that methoxy substitution at positions 2' and 5' in the designed scaffold seemed to be a key feature for the trypanocidal activity. Therefore, the coumarin-chalcone scaffold can be taken into account for further lead optimization and design new and more effective trypanocidal compounds.
\end{abstract}

Keywords: Chagas disease; Chalcone; Coumarin; Cytotoxicity; Natural products; Structure-activity relationship; Trypanosoma cruzi

\section{Introduction}

American Trypanosomiasis or Chagas disease is a chronic parasitosis, caused by the Kinetoplastid parasite Trypanosoma cruzi (T. cruzi), which has afflicted humanity since its earliest presence in the New World [1] but whose true nature as an infectious disease was just discovered a hundred years ago by Carlos Chagas in Minas Gerais, Brazil. An estimated 10 million people are infected with $T$. cruzi worldwide, mostly in Latin America, and more than 25 million people are at risk for the disease.The parasite's biological cycle includes three fundamental forms characterized by the relative positions of the flagellum, kinetoplast, and nucleus [2]: 1) Trypomastigotes: Constitute the infecting form, and are found in mammalian blood and the hindgut of triatomine bugs; they do not multiply. In mammals they are the disseminators of blood- borne infection. 2) Epimastigotes: They represent the parasite's multiplicative form in the triatomid's intestine, and are the predominant form in culture. For this reason, it is the most commonly form used in biochemical studies. 3) Amastigotes: They multiply by means of binary fission inside mammalian host cells, producing their rupture, and liberating trypomastigotes into the bloodstream that can once again invade any nucleated cell. They can be grown in culture in muscle cells, fibroblasts, and macrophages among others [3]

Present treatment for Chagas disease relies on two drugs, Nifurtimox and Benznidazole discovered empirically more than three decades ago $[4,5]$. These drugs are effective for acute infections, but their use for chronic patients remains controversial [6]. Furthermore, studies of the mechanisms of action indicated that their antiparasitic activity is linked to mammalian host toxicity [7]. The efficacy of these drugs also depends on the susceptibility of $T$. cruzi strains and resistance to benznidazole has been reported [8]. Therefore, the discovery of new and more effective drugs that can be well tolerated and safer, is a topic of major interest [9].

Coumarins are a family of natural and/or synthetic compounds with different pharmacological activities [10,11], being one of them the antiparasitic activity $[12,13]$. Some coumarins proved to be important molecules in the regression of the described pathology. Previous studies described that they act by inhibiting GAPDH (enzyme commission number 1.2.1.12), an important protein present in the trypanosomatids glycolytic pathway [14]. It has also been described that some coumarin derivatives are potent growth inhibitors of Leishmania amazonensis causing important changes in the parasite's ultrastructure such as mitochondrial swelling with concentric membranes in the mitochondrial matrix and intense exocytic activity in the region of the flagellar pocket [15].

On the other hand, chalcones are another family of natural and/or synthetic compounds that present a wide range of biological activities $[16,17]$. Some chalcones with important antiparasitic activity have been described $[18,19]$. Previous studies have shown that licochalcone A, present in the Chinese licorice root, altered the ultrastructure and function of the mitochondria of Leishmania species without damaging the organelles of macrophages or the phagocytic function of these cells [20]. It has also been described that antiparasitic activity of some oxygenated chalcones might be the result of interferences with function of the parasite mitochondria [21].

\section{Materials and Method}

\section{Chemistry}

Melting points were determined using a Reichert Kofler thermopan or in capillary tubes on a Büchi 510 apparatus and are uncorrected. $1 \mathrm{H}$ and 13C NMR spectra were recorded on a Bruker AMX spectrometer at 250 and $75.47 \mathrm{MHz}$, respectively, using TMS as internal standard (chemical shifts in $\delta$ values, $\mathrm{J}$ in $\mathrm{Hz}$ ). Mass spectra were obtained using a Hewlett-Packard 5988A spectrometer. Elemental analyses were performed using a Perkin-Elmer 240B microanalyser and were within $\pm 0.4 \%$ of calculated values in all cases. Silica gel (Merck $60,230-00$

*Corresponding author: Saleta Vazquez-Rodriguez, CIQUP/Department of Chemistry and Biochemistry, Faculty of Sciences, University of Porto, Rua Campo Alegre 687, 4169-007 Porto, Portugal, E-mail: svre77@gmail.com

Received March 10, 2015; Accepted April 14, 2015; Published April 16, 2015

Citation: Rodriguez SV, Guíñez RF, Matos MJ, Azar CO, Maya JD, et al. (2015) Synthesis and Trypanocidal Properties of New Coumarin-Chalcone Derivatives. Med chem 5: 173-177. doi:10.4172/2161-0444.1000260

Copyright: (c) 2015 Rodriguez SV, et al. This is an open-access article distributed under the terms of the Creative Commons Attribution License, which permits unrestricted use, distribution, and reproduction in any medium, provided the original author and source are credited. 
mesh) was used for flash chromatography (FC). Analytical thin layer chromatography (TLC) was performed on plates precoated with silica gel (Merck 60 F254, $0.25 \mathrm{~mm}$ ). The purity of the compounds was found to be higher than $95 \%$.

Preparation of 3-acetylcoumarin (1) [22]: A mixture of salicylaldehyde (1 eq.), ethyl acetoacetate (1 eq.) and a few drops of piperidine were mixed for $30 \mathrm{~min}$. at room temperature without any solvent. Reaction was neutralized with $\mathrm{HCl}$ (dil.) and finally the product was isolated by filtration. The final compound was then recrystallized in $\mathrm{EtOH}$.

General procedure for the synthesis of 3-(3- aryl)acryloylcoumarin (2-5) : 3-Acetylcoumarin $(1,1 \mathrm{mmol})$ and the conveniently substituted aromatic aldehyde $(1.1 \mathrm{mmol})$ were dissolved in EtOH $(3 \mathrm{~mL})$ and a catalytic amount of piperidine $(0.05 \mathrm{~mL})$ was added. The reaction mixture was stirred for 4-12 hours under reflux. After completion of reaction (followed by TLC), the solvent was evaporated under vacuum and the dry residue was purified by Flash Chromatography using hexane:acetate $(8: 2)$ as eluent to give the desired products $2-5$.

(E)-3-(3-(4-Methoxyphenyl)acryloyl)coumarin (2): Yield 60\% Mp: 202-203 ${ }^{\circ} \mathrm{C} .1 \mathrm{H} \mathrm{NMR}(250 \mathrm{MHz}, \mathrm{CDCl} 3) \delta \mathrm{ppm} 8.40(\mathrm{~s}, 1 \mathrm{H}), 7.68(\mathrm{~d}, \mathrm{~J}$ $=15 \mathrm{~Hz}, 1 \mathrm{H}), 7.67(\mathrm{~d}, \mathrm{~J}=15 \mathrm{~Hz}, 1 \mathrm{H}), 7.48(\mathrm{t}, \mathrm{J}=7.7 \mathrm{~Hz}, 4 \mathrm{H}), 7.27-7.12$ $(\mathrm{m}, 2 \mathrm{H}), 6.76(\mathrm{~d}, \mathrm{~J}=8.8 \mathrm{~Hz}, 2 \mathrm{H}), 3.69(\mathrm{~s}, 3 \mathrm{H}) .13 \mathrm{C} \mathrm{NMR}(75 \mathrm{MHz}$, CDCl3) $\delta \mathrm{ppm} 186.5,162.2,159.6,155.4,148.0,145.3,134.3,131.0$, $130.2,127.8,125.8,125.1,121.9,118.8,116.9,114.6,55.7 . \mathrm{MS} \mathrm{m} / \mathrm{z}(\%)$ : $307([\mathrm{M}+1]+, 13), 306([\mathrm{M}]+, 100), 277$ (18), 161 (51), 133 (39), 89 (51).

(E)-3-(3-(2,4-Dimethoxyphenyl)acryloyl)coumarin (3): Yield 91\%. Mp: $192-194^{\circ} \mathrm{C}$. H NMR (250 MHz, CDCl3) $\delta$ ppm. 8.37 (s, 1H), 8.00 $(\mathrm{d}, \mathrm{J}=15.8 \mathrm{~Hz}, 1 \mathrm{H}), 7.72(\mathrm{~d}, \mathrm{~J}=15.7 \mathrm{~Hz}, 1 \mathrm{H}), 7.55-7.39(\mathrm{~m}, 3 \mathrm{H})$, $7.27-7.11(\mathrm{~m}, 2 \mathrm{H}), 6.36(\mathrm{dd}, \mathrm{J}=8.6,2.4 \mathrm{~Hz}, 1 \mathrm{H}), 6.29(\mathrm{~d}, \mathrm{~J}=2.4 \mathrm{~Hz}$, $1 \mathrm{H}), 3.73$ (s, 3H), 3.69 (s, 3H). 13C NMR (75 MHz, CDCl3) $\delta \mathrm{ppm} \delta$ $186.7,163.4,160.7,159.3,155.1,147.3,140.7,133.8,131.1,129.8,126.0$, $124.8,121.9,118.7,117.1,116.6,105.5,98.3,55.5,55.5 . \mathrm{MS} \mathrm{m} / \mathrm{z}(\%): 337$ ([M+1]+, 24), $336([\mathrm{M}]+, 100), 305$ (42), 191 (53), 145 (41), 137 (29), $92(18), 77$ (15)

(E)-3-(3-(2,4,5-Trimethoxyphenyl)acryloyl)coumarin(4): Yield 96\%. Mp: $190-192^{\circ} \mathrm{C} .1 \mathrm{H} \mathrm{NMR}(250 \mathrm{MHz}, \mathrm{CDCl} 3) \delta \mathrm{ppm} 8.38(\mathrm{~s}, 1 \mathrm{H})$, $8.05(\mathrm{~d}, \mathrm{~J}=15.8 \mathrm{~Hz}, 1 \mathrm{H}), 7.65(\mathrm{~d}, \mathrm{~J}=15.7 \mathrm{~Hz}, 1 \mathrm{H}), 7.56-7.39(\mathrm{~m}, 2 \mathrm{H})$, $7.27-7.12(\mathrm{~m}, 2 \mathrm{H}), 7.01(\mathrm{~s}, 1 \mathrm{H}), 6.33(\mathrm{~s}, 1 \mathrm{H}), 3.78(\mathrm{~s}, 3 \mathrm{H}), 3.74(\mathrm{~d}, \mathrm{~J}=$

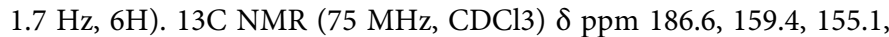
153.0, 147.4, 143.3, 140.3, 133.9, 129.9, 126.0, 125.0, 124.9, 121.6, 118.7, $116.7,115.5,111.1,96.6,56.5,56.4,56.1 . \mathrm{MS} \mathrm{m} / \mathrm{z}(\%): 367([\mathrm{M}+1]+, 28)$, 366 ([M]+, 100), 336 (32), 293 (42), 161 (91), 133 (19), 89 (17).

(E)-3-(3-(2,5-Dimethoxyphenyl)acryloyl)coumarin (5): Yield 83\%. Mp: $114-115$ oC $1 \mathrm{H}$ NMR $(250 \mathrm{MHz}, \mathrm{CDCl} 3) \delta \mathrm{ppm} 8.54(\mathrm{~s}, 1 \mathrm{H}), 8.18$ $(\mathrm{d}, \mathrm{J}=15.8 \mathrm{~Hz}, 1 \mathrm{H}), 7.93(\mathrm{~d}, \mathrm{~J}=15.8 \mathrm{~Hz}, 1 \mathrm{H}), 7.73-7.57(\mathrm{~m}, 2 \mathrm{H}), 7.44$ - $7.28(\mathrm{~m}, 2 \mathrm{H}), 7.21(\mathrm{~d}, \mathrm{~J}=3.0 \mathrm{~Hz}, 1 \mathrm{H}), 7.00-6.79(\mathrm{~m}, 2 \mathrm{H}), 3.87(\mathrm{~s}, 3 \mathrm{H})$, 3.81 (s, 3H). 13C NMR (75 MHz, CDCl3) $\delta$ ppm 186.8, 159.3, 155.2, 153.6, 153.5, 147.7, 140.2, 134.0, 129.9, 125.7, 124.9, 124.5, 124.3, 118.6, 118.2, 116.6, 113.4, 112.5, 56.1, 55.8. MS m/z (\%): 337 ([M+1]+, 10), 336 ([M]+, 29), 306 (34), 305 (100), 173 (23), 89 (26).

\section{Biological assays}

Epimastigote viability study: Trypanocidal activity was evaluated against the T. cruzi epimastigote stage (clone Dm28c). It was measured through the MTT assay [23] using $0.22 \mathrm{mg} \mathrm{mL}$ phenazine metosulfate (as electron carrier). T. cruzi epimastigotes Dm28c strain, from our own collection (Programa de Farmacología Molecular y Clínica, Facultad de Medicina, Universidad de Chile) were grown at $28^{\circ} \mathrm{C}$ in Diamond's monophasic medium, as reported earlier but replacing blood by $4 \mu \mathrm{M}$ hemin [24]. Fetal calf serum was added to a final concentration of $5 \%$. In this colorimetric were dissolved in DMSO and were added to $3 \mathrm{x}$ 106 parasites mL- 1 at $10 \mu \mathrm{M}$ final concentrations in RPMI 1640 culture medium for $24 \mathrm{~h}$ at $28^{\circ} \mathrm{C}$. DMSO final concentration was less than $0.1 \%$ $\mathrm{v} / \mathrm{v}$. Likewise, nifurtimox was added as positive control. Tetrazolium salt was added at a final concentration of $0.5 \mathrm{mg} \mathrm{mL}-1$, incubated at $28^{\circ} \mathrm{C}$ for $4 \mathrm{~h}$ and then solubilized with $10 \%$ sodium dodecyl sulfate/ 0.1 $\mathrm{mM} \mathrm{HCl}$ and incubated overnight. After incubation time, it was determined the number of viable parasites by absorbance measures at $570 \mathrm{~nm}$ in a multi-well plate reader (Asys Expert Plus@), Austria). Untreated parasites were used as controls (100\% of viability). Results are reported in Table 1 as the percentage of non-viable epimastigotes regarding the control.

Trypomastigote viability study: Cell culture and in vitro infection with T. cruzi (Dm28c strain) trypomastigote: Vero cells were infected with Dm28c trypomastigotes at a 1:3 (cell:parasite) ratio. T. cruzi trypomastigotes were initially obtained from primary cultures of peritoneal macrophage from chagasic mice. Vero cells were cultured in 5\% fetal bovine serum supplemented RPMI 1640 medium in humidified air with $5 \% \mathrm{CO}_{2}$ at $37^{\circ} \mathrm{C}$. Vero cell cultures were then infected with trypomastigotes were incubated at $37^{\circ} \mathrm{C}$ in humidified air and 5\% CO2, for 5-7 days. After that time, the culture medium was collected, centrifuged at $500 \mathrm{~g}$ for $5 \mathrm{~min}$, and the trypomastigotecontaining pellet was re- suspended in free-serum RPMI 1640 and penicillin- streptomycin at a final density of $1 \times 10^{7}$ parasites $/ \mathrm{mL}$. Trypomastigote viability assays were performed using the MTT reduction method as described previously. $1 \times 107$ parasites $/ \mathrm{mL}$ were incubated in free-serum RPMI 1640 culture medium at $37^{\circ} \mathrm{C}$ during $24 \mathrm{~h}$ with or without the studied compounds. An aliquot of the parasite suspension was extracted and incubated in a 96-flat bottom well plate and MTT was added at $0.5 \mathrm{mg} / \mathrm{mL}$ final concentration and using 0.22 $\mathrm{mg} \mathrm{mL} \mathrm{m}^{-1}$ phenazine metosulfate (as electron carrier), incubated at $28^{\circ} \mathrm{C}$ during $4 \mathrm{~h}$ and then made soluble with $10 \%$ SDS- $-0.1 \mathrm{mM} \mathrm{HCl}$ and incubated overnight. Formazan formation was measured at 570 $\mathrm{nm}$, with reference wavelength at $690 \mathrm{~nm}$, in a multi-well plate reader (Asys Expert Plus $\odot$, Austria). Untreated parasites were used as controls (100\% of viability). Results are reported in Table 1 as the percentage of non-viable parasites regarding the control.

Amastigote viability study: Amastigotes were obtained with the same technique [23] used for trypomastigotes, but Vero cells were infected with $\mathrm{Dm} 28 \mathrm{c}$ trypomastigotes at a 1:10 (cell: parasite) ratio, which induces cell rupture and release of amastigotes into the medium after 5 days. The culture medium was collected, centrifuged at $500 \mathrm{~g}$ for $5 \mathrm{~min}$, and the amastigote-containing pellet was re-suspended in freeserum RPMI 1640 and penicillin-streptomycin at a final density of $2 \times 10^{7}$ amastigotes $/ \mathrm{mL}$. Amastigote viability assays were performed using the MTT reduction method as described previously. $2 \times 10^{7}$ parasites/ $\mathrm{mL}$ were incubated in free-serum RPMI 1640 culture medium at $37^{\circ} \mathrm{C}$ during $24 \mathrm{~h}$ with or without the compound 4 . An aliquot of the parasite suspension was extracted and incubated in a 96-flat bottom well plate and incubated at $28^{\circ} \mathrm{C}$ during $4 \mathrm{~h}$ and then made soluble with $10 \%$ SDS-0.1 mM HCl and incubated overnight. Formazan formation was measured at $570 \mathrm{~nm}$, with reference wavelength at $690 \mathrm{~nm}$, in a multiwell plate reader (Asys Expert Plus $\odot$, Austria). Untreated parasites were used as controls (100\% of viability). Results are reported in Table 1 as the percentage of non-viable parasites regarding the control.

Cytotoxicity assay: Green Monkey (Cercopithecus aethiops) renal fibroblast like cells (VERO cells (ATCC ${ }^{\oplus}$ CCL-81)) were grown in RPMI medium enriched with 5\% fetal bovine (FBS) serum and antibiotics (penicillin-streptomycin). Cells were grown at $37^{\circ} \mathrm{C}$ in a 
humid atmosphere at $5 \% \mathrm{CO}_{2}$ for $96 \mathrm{~h}$, replacing the medium every $24 \mathrm{~h} \mathrm{[25].}$

The effect of drug treatments on RAW 264.7 cells was evaluated through the MTT assay as viability test [26]. Briefly, $10 \mu \mathrm{L}$ of 5 $\mathrm{mg} / \mathrm{mL}$ tetrazolium dye (MTT; 3[4,5- dimethylthiazol-2-yl]-2,5diphenyltetrazolium bromide) plus $0.22 \mathrm{mg} / \mathrm{mL}$ phenazine metosulfate (electron carrier), were added to each well containing RAW 264.7 cell culture in $100 \mu \mathrm{L}$ RPMI 1640 without phenol red.

Compounds under study, dissolved in DMSO, were added to the culture media. DMSO final concentration was less than $0.25 \%$ $\mathrm{v} / \mathrm{v}$. After incubation for $4 \mathrm{~h}$ at $37^{\circ} \mathrm{C}$, the generated water insoluble formazan dye was dissolved by addition of $100 \mu \mathrm{L}$ of $10 \% \mathrm{w} / \mathrm{v}$ SDS in $0.01 \mathrm{M} \mathrm{HCl}$. The plates were further incubated overnight at $37^{\circ} \mathrm{C}$, and optical density (OD) of the wells was determined using a microplate reader (Asys Expert Plus $\odot$, Austria) at $570 \mathrm{~nm}$. Under these conditions, the OD is directly proportional to the viable cell number in each well. All experiments were performed at least three times and data are shown as means and their standard deviations from triplicate cultures. Results are reported as the percentage of non-viable VERO or RAW 264.7 cells regarding the control.

\section{Results and Discussions}

Based on the previously mentioned features of coumarins and chalcones, and in our experience with 3-amido and 3-benzoyl coumarins as potential trypanocidal agents, [12,27] we decided to design and synthesize new coumarin-chalcone hybrid compounds (Figure 1) with the aim of finding new chemical entities with trypanocidal activity.

Compounds 2-5 were efficiently synthesized according to the protocol outlined in Figure 2. Compounds were prepared in a two-step synthetic route. In the first step the 3-acetylcoumarin (1) was prepared with $93 \%$ yield by a Knoevenagel reaction using salicylaldehyde and ethyl acetoacetate without solvent and employing piperidine in catalytic<smiles>O=c1ccc2ccccc2o1</smiles><smiles>O=C(/C=C/c1ccccc1)c1ccccc1</smiles><smiles></smiles>

Figure 1: Design of the coumarin-chalcone hybrid scaffold.

amount at room temperature [22]. The last step involves a ClaisenSchmidt condensation in EtOH, using piperidine as base, mixed with the corresponding aromatic aldehydes under reflux to afford the desired final compounds $2-5$ in good to excellent yields (60-96\%).

It is known that the activity against one form of the parasite life cycle does not ensure similar activities against the others. Morphologic changes occur during the transformation between cycle. The sensibility of the different forms to the drugs is, therefore, modified [28].

Compounds 2-5 were studied in the epimastigote, trypomastigote stages of the T.cruzi parasite and compound 5 was additionally studied in the amastigote stage. Results are presented in Table 1.

Compounds were generally more active against the trypomastigote stage, which is the infective form in the mammalian host, since it is

Step 1: Synthesis of the precursor 3-acetylcoumarin<smiles>CCOC(=O)CC(C)=O</smiles>

Step 2: Synthesis of the final compounds $\mathbf{2 - 5}$<smiles>[R2]C(=O)c1cc([R16])c([R16])cc1/C=C/C(=O)c1cc(/C=C/C(=O)c2cc3ccccc3oc2=O)c([R3])cc1[R16]</smiles>

1

$$
\begin{aligned}
& 2 \mathrm{R}_{2^{\prime}}=\mathrm{R}_{5^{\prime}}=\mathrm{H} ; \mathrm{R}_{4^{\prime}}=\mathrm{OMe} \\
& 3 \mathrm{R}_{2^{\prime}}=\mathrm{R}_{4^{\prime}}=\mathrm{OMe} ; \mathrm{R}_{5^{\prime}}=\mathrm{H} \\
& 4 \mathrm{R}_{2^{\prime}}=\mathrm{R}_{4^{\prime}}=\mathrm{R}_{5^{\prime}}=\mathrm{OMe} \\
& 5 \mathrm{R}_{2^{\prime}}=\mathrm{R}_{5^{\prime}}=\mathrm{OMe} ; \mathrm{R}_{4^{\prime}}=\mathrm{H}
\end{aligned}
$$

Figure 2: Synthesis of compounds $2-5$ in a two-step route by a Knoevenagel reaction followed by a Claisen-Schmidt condensation. 


\begin{tabular}{|c|c|c|c|c|c|c|}
\hline \multirow{2}{*}{ Compound } & \multicolumn{7}{|c|}{ Trypanocidal activity (\%) } & \\
\cline { 2 - 7 } & \multicolumn{2}{|c|}{ Epimastigote } & Trypomastigote & \multicolumn{2}{c|}{ Amastigote } \\
\cline { 2 - 7 } & $\mathbf{1 0}$ & $\mathbf{1 0 0}$ & $\mathbf{1 0}$ & $\mathbf{1 0 0}$ & $\mathbf{1 0}$ & $\mathbf{1 0 0}$ \\
& $\boldsymbol{\mu M}$ & $\mathbf{\mu M}$ & $\mathbf{\mu M}$ & $\boldsymbol{\mu M}$ & $\boldsymbol{\mu M}$ & $\boldsymbol{\mu M}$ \\
\hline $\mathbf{2}$ & NA & $10 \pm 1$ & $12 \pm 1$ & $34 \pm 1$ & - & - \\
\hline $\mathbf{3}$ & NA & $11 \pm 1$ & $27 \pm 1$ & $37 \pm 2$ & - & - \\
\hline $\mathbf{4}$ & $12 \pm 1$ & $29 \pm 2$ & $11 \pm 1$ & $53 \pm 4$ & - & - \\
\hline $\mathbf{5}$ & $15 \pm 1$ & $78 \pm 6$ & $71 \pm 6$ & $96 \pm 6$ & $73 \pm 7$ & $100 \pm 4$ \\
\hline Nifurtimox & $52 \pm 2$ & $100 \pm 3$ & $36 \pm 3$ & $100 \pm 2$ & $45 \pm 3$ & $100 \pm 3$ \\
\hline
\end{tabular}

Values (mean $\pm S D$ ) were obtained from three independent experiments.

NA inactive at concentration tested.

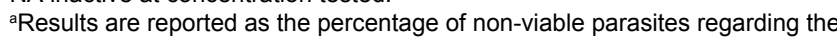
control at 10 and $100 \mu \mathrm{M}$.

- Not tested

Table 1: Trypanocidal activity in different parasite stages for compounds $2-5$ and the reference compound Nifurtimox at two different concentrations.

\begin{tabular}{|c|c|c|}
\hline \multirow{2}{*}{ Parasite stage } & \multicolumn{2}{|c|}{ IC $_{50}(\boldsymbol{\mu M})$} \\
\hline Epimastigote & $17.4 \pm 5.1$ & Compound 5 \\
\hline Trypomastigote & $10.0 \pm 0.4$ & $46.8 \pm 3.7$ \\
\hline Amastigote & $18.6 \pm 2.6$ & $2.6 \pm 0.2$ \\
\hline
\end{tabular}

The results are the means of three different experiments with a SD less than $10 \%$ in all cases.

${ }_{\text {a }} \mathrm{C}_{50}$ : concentration that produces $50 \%$ of inhibitory effect.

Table 2: IC50 values for compound 5 and Nifurtimox in different parasite stages.

\begin{tabular}{|c|c|c|c|c|}
\hline \multirow{2}{*}{ Compound } & \multicolumn{4}{|c|}{ Cytotoxicity (\%)a } \\
\cline { 2 - 5 } & \multicolumn{2}{|c|}{ RAW $\mathbf{2 6 4 . 7}$} & \multicolumn{2}{c|}{ VERO } \\
\cline { 2 - 5 } & $\mathbf{1 0} \boldsymbol{\mu M}$ & $\mathbf{1 0 0} \boldsymbol{\mu M}$ & $\mathbf{1 0} \boldsymbol{\mu M}$ & $\mathbf{1 0 0} \boldsymbol{\mu M}$ \\
\hline 2 & $36.9 \pm 2.6$ & $43.6 \pm 3.9$ & $16.4 \pm 1.2$ & $46.5 \pm 3.9$ \\
\hline 3 & $1.4 \pm 0.1$ & $24.2 \pm 2.4$ & $4.7 \pm 0.3$ & $19.0 \pm 1.7$ \\
\hline 4 & $58.2 \pm 4.4$ & $95.1 \pm 7.8$ & $15.5 \pm 1.4$ & $35.9 \pm 2.9$ \\
\hline 5 & $73.2 \pm 5.9$ & $90.9 \pm 8.3$ & $25.7 \pm 2.4$ & $91.8 \pm 8.8$ \\
\hline Nifurtimox & NA & NA & NA & NA \\
\hline
\end{tabular}

All the experiments were carried out in triplicate, and the data represent the mean values ( \pm S.D.)

NA inactive at concentration tested

${ }^{a}$ Results are reported as the percentage of non-viable VERO or RAW 264.7 cells regarding the control.

Table 3: Cytotoxicity of compounds 2-5 and Nifurtimox against RAW 264.7 mouse macrophage cells and VERO cells.

\begin{tabular}{|c|c|c|}
\hline \multirow{2}{*}{ Cell line } & \multicolumn{2}{|c|}{ IC $_{50}(\mu \mathrm{M})$} \\
\cline { 2 - 3 } & Nifurtimox & Compound 5 \\
\hline RAW 264.7 & $263.4 \pm 25.4$ & $6.1 \pm 0.5$ \\
\hline VERO & $>100$ & $56.8 \pm 5.4$ \\
\hline
\end{tabular}

The results are the means of two different experiments with a SD less than $10 \%$ in all cases.

${ }^{a} \mathrm{CC}_{50}$ : concentration that produces $50 \%$ of inhibitory effect.

Table 4: $I C_{50}$ in mammalian cell lines.

the disseminator of blood-borne infection. The most active compound of the series was compound 5. At the lowest concentration tested $(10 \mu \mathrm{M})$, compound 5 was twice as active as Nifurtimox against the trypomastigote stage of the parasite.

A structure-activity relationship study (SAR) showed that compound 2, bearing just one methoxy group at 4' position was the less active compound of the series. When one additional methoxy group was added to the molecule at positions 2' (compound 3) or even two methoxy groups at positions 2' and 5' (compound 4), the trypanocydal activity increases compared to compound 2. However, when there was no methoxy group at position 4 , and only two methoxy groups were positioned at 2' and 5' (compound 5), the trypanocidal activity increased significantly and this fact could indicate that methoxy substitution at positions 2' and 5', and no substitution at position 4' was a key feature for the trypanocidal activity of this scaffold.

Since compound 5 presented the most promising trypanocidal activity, its $\mathrm{IC}_{50}(\mu \mathrm{M})$ against the three parasite stages was calculated and compared with the $\mathrm{IC}_{50}$ values for the current drug Nifurtimox. Results are shown in Table 2. It was observed that compound 5 ( $\mathrm{IC}_{50}$ $=2.6 \mu \mathrm{M})$ was 4 times more active than Nifurtimox $\left(\mathrm{IC}_{50}=10.0 \mu \mathrm{M}\right)$ against the trypomastigote stage parasite. In addition, against the amastigote stage, compound 5 was also more that 6 times more active than Nifurtimox $\left(\mathrm{IC}_{50}=2.9\right.$ and $18.9 \mu \mathrm{M}$, respectively)

Cytotoxicity assays, in murin RAW 264.7 macrophages and VERO cells were performed, and results are summarized in Table 3. It was observed that compounds 2-4 were less cytotoxic at low concentration $(10 \mu \mathrm{M})$ than compound 5 , which resulted cytotoxic at 10 and $100 \mu \mathrm{M}$ for RAW 264.7, and it was especially cytotoxic against VERO cells at the highest concentration tested.

Compound 5 was the most cytotoxic compound, and in order to quantify the sensibility against the two mammalian cell lines the $\mathrm{IC}_{50}(\mu \mathrm{M})$ was calculated and compared to Nifurtimox. Results are presented in Table 4.

The $\mathrm{IC}_{50}$ values in parasitic stages and in mammalian cell showed that compound 5 presented the most promising trypanocidal activity, but it was also toxic in mammalian cell lines.

\section{Conclusion}

In conclusion, a new series of coumarin-chalcone hybrid compounds was design and synthesized as trypanocidal agents. Compounds were tested against the epimastigote, trypomastigote and amastigote stages of the T. cruzi parasite. All compounds were more active against the trypomatigote stage, being the most promising molecule compound 5 , which presented $\mathrm{IC}_{50}$ values 4 and 6 times higher than Nifurtimox for the trypomastigote and amastigote stages, respectively. However, compound 5 showed high cytotoxicity values in RAW 264.7 and VERO cells. Methoxy substitution at positions 2 ' and 5 ' of the designed scaffolds seemed to be a key feature for the trypanocidal activity. Therefore, the coumarin-chalcone scaffold can be taken into account for further lead optimization and design new and more effective trypanocidal compounds.

\section{Acknowledgements}

The authors thank the Foundation for Science and Technology (FCT) of Portugal (PEst-C/QUI/UI0081/2013 project) and the FONDECYT (projects 1150175 and 1130189) and Anillo ACT112 (Chile). S.V.R. thanks to the University of Porto for the postdoctoral grant NORTE-07-0124-FEDER-000065. RF gratefully acknowledges CONICYT-Chile for his PhD scholarship (No. 21100132) and his PhD grant (No.24121574). M.J.M. thanks to the Fundação para a Ciência e Tecnologia (FCT), POPH (Programa Operacional Potencial Humano) and QREN (Quadro de Referência Estratégica Nacional) for the postdoctoral grant (SFRH/ BPD/95345/2013)

\section{References}

1. Aufderheide AC, Salo W, Madden M, Streitz J, Buikstra J, et al. (2004) A 9,000year record of Chagas' disease. Proc Natl Acad Sci U S A 101: 2034-2039.

2. Prata $A$ (2001) Clinical and epidemiological aspects of Chagas disease. Lancet Infect Dis 1: 92-100.

3. Faundez M, Pino L, Letelier P, Ortiz C, Lopez R, et al. (2005) Buthionine sulfoximine increases the toxicity of nifurtimox and benznidazole to Trypanosoma cruzi. Antimicrob Agents Chemother 49: 126-130.

4. Boiani M, Piacenza L, Hernández $P$, Boiani L, Cerecetto $H$, et al. (2010) Mode of action of Nifurtimox and $\mathrm{N}$ - oxide-containing heterocycles against Trypanosoma cruzi: Is oxidative stress involved? Biochem Pharmacol 79 1736-1745. 
Citation: Rodriguez SV, Guínez RF, Matos MJ, Azar CO, Maya JD, et al. (2015) Synthesis and Trypanocidal Properties of New Coumarin-Chalcone Derivatives. Med chem 5: 173-177. doi:10.4172/2161-0444.1000260

5. Hall BS, Wilkinson SR (2012) Activation of benznidazole by trypanosomal type I nitroreductases results in glyoxal formation. Antimicrob Agents Chemother 56: $115-123$

6. Croft SL, Barrett MP, Urbina JA (2005) Chemotherapy of trypanosomiases and leishmaniasis. Trends Parasitol 21: 508-512.

7. Urbina JA (2010) Specific chemotherapy of Chagas disease: relevance, current limitations and new approaches. Acta Trop 115: 55-68.

8. Andriani G, Chessler AD, Courtemanche G, Burleigh BA, Rodriguez A (2011) Activity in vivo of anti-Trypanosoma cruzi compounds selected from a high throughput screening. PLoS Negl Trop Dis 5: e1298.

9. Gutiérrez B, Muñoz C, Osorio L, Fehér K, Illyés TZ, et al. (2013) Aromatic glycosyl disulfide derivatives: Evaluation of their inhibitory activities against Trypanosoma cruzi. Bioorg Med Chem Lett 23: 3576-3579.

10. Borges F, Roleira F, Milhazes N, Santana L, Uriarte E (2005) Simple coumarins and analogues in medicinal chemistry: occurrence, synthesis and biological activity. Curr Med Chem 12: 887-916.

11. Borges MFM, Roleira FMF, Uriarte E, Santana L (2009) Simple Coumarins: Privileged Scaffolds in Medicinal Chemistry. Front Med Chem 4: 23-85.

12. Guinez RF, Matos MJ, Vazquez-Rodriguez S, Santana L, Uriarte E, et al. (2013) Synthesis and evaluation of antioxidant and trypanocidal properties of a selected series of coumarin derivatives. Future Med Chem 5: 1911-1922.

13. Reyes-Chilpa R, Estrada-Muniz E, Vega-Avila E, Abe F, Kinjo J, et al. (2008) Trypanocidal constituents in plants: 7. Mammea-type coumarins. Mem Inst Oswaldo Cruz 103: 431-436.

14. Freitas RF, Prokopczyk IM, Zottis A, Oliva G, Andricopulo AD, et al. (2009) Discovery of novel Trypanosoma cruzi glyceraldehyde-3- phosphate dehydrogenase inhibitors. Bioorg Med Chem 17: 2476-2482.

15. Brenzan MA, Nakamura CV, Prado Dias Filho B, Ueda-Nakamura T, Young MC, et al. (2007) Antileishmanial activity of crude extract and coumarin from Calophyllum brasiliense leaves against Leishmania amazonensis. Parasitol Res 10: 715-722.

16. Sahu NK, Balbhadra SS, Choudhary J, Kohli DV (2012) Exploring pharmacological significance of chalcone scaffold: a review. Curr Med Chem 19: $209-225$
17. Singh P, Anand A2, Kumar V3 (2014) Recent developments in biological activities of chalcones: a mini review. Eur J Med Chem 85: 758-777.

18. Lunardi F, Guzela M, Rodrigues AT, Correa R, Eger-Mangrich I, et al. (2003) Trypanocidal and leishmanicidal properties of substitution-containing chalcones. Antimicrob Agents Chemother 47: 1449-1451.

19. Sinha S, Medhi B, Sehgal R (2013) Chalcones as an Emerging Lead Molecule for Antimalarial Therapy: A Review. J Mod Med Chem 1: 64-77.

20. Zhai L, Blom J, Chen M, Christensen SB, Kharazmi A (1995) The antileishmanial agent licochalcone $A$ interferes with the function of parasite mitochondria Antimicrob Agents Chemother 39: 2742-2748.

21. Zhai L, Chen M, Blom J, Theander TG, Christensen SB, et al. (1999) The antileishmanial activity of novel oxygenated chalcones and their mechanism of action. J Antimicrob Chemother 43: 793-803.

22. Sugino T, Tanaka K (2001) Solvent-free coumarin synthesis. Chem Lett 30 110-111.

23. Bisby RH, Brooke R, Navaratnam S (2008) Effect of antioxidant oxidation potential in the oxygen radical absorption capacity (ORAC) assay. Food Chem 108: 1002-1007.

24. Vieites M, Otero L, Santos D, Toloza J, Figueroa R, et al. (2008) Platinum(II) metal complexes as potential anti-Trypanosoma cruzi agents. J Inorg Biochem 102: $1033-1043$

25. Salas C, Tapia RA, Ciudad K, Armstrong V, Orellana M, et al. (2008) Trypanosoma cruzi: activities of lapachol and alpha- and beta-lapachone derivatives against epimastigote and trypomastigote forms. Bioorg Med Chem 16: 668-674.

26. Mosmann T (1983) Rapid colorimetric assay for cellular growth and survival: application to proliferation and cytotoxicity assays. J Immunol Methods 65: 5563.

27. Vazquez-Rodriguez S, Figueroa-Guíñez R, Matos MJ, Santana L, Urirarte E et al. (2013) Synthesis of coumarin-chalcone hybrids and evaluation of their antioxidant and trypanocidal properties. Med Chem Commun 4: 993-1000.

28. Demoro B, Rossi M, Caruso F, Liebowitz D, Olea-Azar C, et al. (2013) Potential mechanism of the anti-trypanosomal activity of organoruthenium complexes with bioactive thiosemicarbazones. Biol Trace Elem Res 153: 371-381. 